\title{
Perspectivas científicas sobre la vacunación del covid-19 conectadas con organizaciones en Latinoamérica
}

Perspectivas científicas sobre a vacinação da covid-19 conectadas com organizações na América Latina

Scientific perspectives on COVID-19 vaccination connected with organizations in Latin America

\section{Entrevista}

Alexis Kalergis

Xinia Fernández Delgado

Mellanie Fontes-Dutra

\section{Entrevistadora}

\section{Claudia Montero-Liberona}

- Profesora Asistente del Departamento de Comunicación Aplicada de la Facultad de Comunicaciones de la Pontificia Universidad Católica de Chile (UC).

- $\quad$ Investigadora del Centro de Medicina Traslacional en Endocrinología (Cetren UC) de la UC.

- Doctorado en Comunicación por la University of Illinois Urbana Champaign.

- E-mail: clmonter@uc.cl 


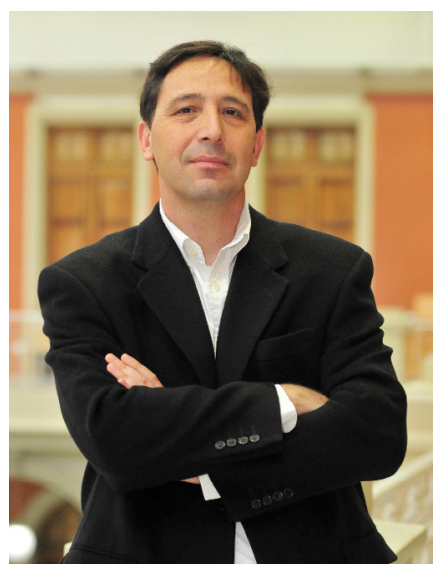

\section{Alexis Kalergis}

- Doctor en Microbiología e Inmunología del Albert Einstein College of Medicine. - $\quad$ Profesor Titular de la Pontificia Universidad Católica de Chile.

- $\quad$ Profesor visitante de las universidades de lowa, Nantes y el Albert Einstein.

- Ha dictado cientos conferencias y ha publicado 270 artículos científicos.

- Ha sido premiado por la Helen Hay Whitney Fellowship, la TWAS, la World Intellectual Property Organization, la Federation of Clinical Immunology Societies, con el premio Nacional de Innovación Avonni, el premio Abdón Cifuentes y al Mérito Andrés Bello.

- Director del Instituto Milenio de Inmunología e Inmunoterapia, perteneciente a la Red de Centros de Excelencia de la Federation of Immunology Societies y de la Vaccine and Therapy Evaluating Units de Estados Unidos.

- $\quad$ Miembro del Centro de Medicina Traslacional en Endocrinología (Cetren UC), de la Facultad de Medicina UC, donde trabaja en el área de inmunología y endocrinología.

- Director de los estudios científico-clínicos de la vacuna Sinovac a Chile, que dieron acceso a las dosis necesarias para la vacunación masiva en el país.

- Ha sido parte de comisiones gubernamentales y legislativas para fortalecer la institucionalidad científica en Chile. Desarrolló la primera vacuna contra el virus respiratorio sincicial en Chile, contando con patentes en Estados Unidos y China. Está trabajando en la formulación de una vacuna que está diseñada para ser utilizada desde el nacimiento para combatir el coronavirus.

- E-mail: akalergis@uc.cl

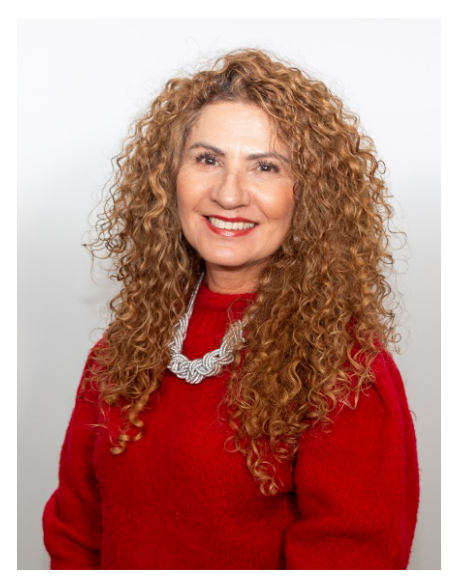

\section{Xinia Fernández Delgado}

- $\quad$ Periodista.

- $\quad$ Directora de Comunicación en Caja Costarricense de Seguro Social (CCSS).

- EstudióCiencias de la Comunicación Colectiva en la Universidad de Costa Rica (UCR).

Realizó estudios en producción radiofónica en Quito, Ecuador.

Diplomada en Altos Estudios de Seguridad Social por el Centro Interamericano de Estudios de Seguridad Social, en México.

Realizó estudios en comunicación programa AID, Estados Unidos.

- Cuenta con un diplomado en comunicación de riesgo.

- $\quad$ Tiene 35 años de experiencia en comunicación en salud.

- $\quad$ E-mail: xfernand@ccss.sa.cr

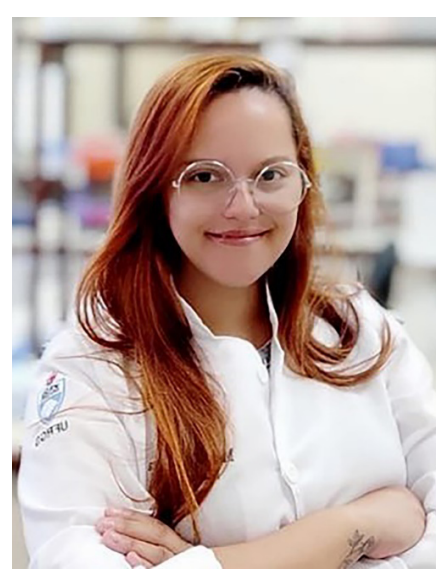

\section{Mellanie Fontes-Dutra}

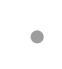

-

$\bullet$

$\bullet$

$\cdot$

E-mail: dutra.mellanie@gmail.com mia del covid-19.

Becaria postdoctoral en la Universidad Federal de Rio Grande do Sul (UFRGS). Maestría y doctorado en Neurociencias por la UFRGS.

Licenciada en Biomedicina por la UFRGS.

Su investigación se centra en las vías etiológicas y fisiopatológicas relacionadas con el trastorno del espectro autista (TEA), utilizando un modelo animal bien establecido para TEA.

Divulgadora de la Ciencia centrada en información científica sobre la pande- 
C omo ha presagiado la revista Times a inicios de 2021, este año estará marcado por los procesos de vacunación en todo el mundo. La situación del covid-19 ha sido un denominador común en la mayoría de los países latinoamericanos, atentos a nuevos avances científicos en vacunas y sus dosis para la población. Hoy, contar con una comunicación en ciencia constituye un desafío que no todas las naciones han desarrollado. Más aún, permitir a los ciudadanos comprender e interpretar el significado de informaciones correctas y verdaderas vinculadas a los procesos de la pandemia resulta fundamental en los procesos de comunicación. Para ahondar más estas necesidades y su vinculación con el mundo de las organizaciones, Organicom conversó con tres destacadas figuras conectadas al mundo de la ciencia en Latinoamérica entre los meses de abril y mayo del 2021. En sus perspectivas se recogen claves que pueden aportar al avance de un bienestar social colectivo en Latinoamérica.

Primeramente, Organicom dialogó con el Dr. Alexis Kalergis, de Chile, quien entregó una visión macro acerca de la situación del covid-19 en Latinoamérica. En seguida, se entrevistó a la Dra. Xinia Fernández Delgado, de Costa Rica, que otorgó una visión estratégica e inspiradora sobre la importancia que tiene la comunicación en los procesos de vacunación y su vinculación con organizaciones internacionales. Finalmente, este ciclo de entrevistas culminó con una conversación con la Dra. Mellanie Fontes-Dutra, de Brasil, enfocándose en la realidad de su país y relevando la importancia que tiene superar informaciones falsas, desinformación e información engañosa vinculada a los procesos del covid-19.

Las conversaciones fueron productivas y ciertamente no terminan aquí. Cada uno de los expertos entrevistados entregó una perspectiva de la pandemia desde su propio país y área de especialidad. A partir de estas entrevistas es posible realizar un llamado a luchar por las mismas causas desde la comunicación de la ciencia, acallando la información falsa, las conceptualizaciones erradas y motivando a los ciudadanos a estar atentos para contribuir con la formación de un bienestar social colectivo. Este es nuestro desafío.

Montero-Liberona - ¿Cómo abordaría usted el tema sobre las vacunas y el covid-19 en América Latina?

Kalergis - Tal como se ha observado para varias de las herramientas de salud para afrontar la pandemia, se ha dejado en evidencia la dificultad en el acceso a las vacunas que han sufrido la mayoría de los países en Latinoamérica. Esta situación ha tenido impactos directos sobre la salud de su población, acumulando la región más del 30\% del total de muertes por covid-19 en el planeta. Lamentablemente, esta situación también ha afectado a otros países del mundo. Considero que un problema global como es la pandemia causada por el coronavirus y la emergencia sanitaria que esta significa, debería tener soluciones globales, por eso, es tan relevante el rol del Fondo de Acceso Global para Vacunas contra la Covid-19 (COVAX), que tiene como objetivo garantizar el acceso equitativo de vacunas contra el coronavirus. Sin duda, se deberían impulsar más iniciativas multilaterales como esta.

Montero-Liberona - ¿Y cómo caracterizaría usted las comunicaciones en América Latina respecto a la vacunación del covid-19?

Kalergis - Creo que, si bien los esfuerzos comunicacionales han ido en la dirección correcta, sería importante fortalecer la transmisión de la evidencia científica relativa a la seguridad, eficacia y efectividad de las vacunas, pero en términos simples y comprensible para la población general. La mayoría de los países, a través de sus organismos oficiales, han resaltado los beneficios y ventajas de recibir una vacuna contra el covid-19. Sin embargo, es necesario fortalecer esta política de comunicación científica para reforzar la seguridad y la eficacia de las vacunas dirigida, en particular, a grupos más reacios a vacunarse y así aumentar la cobertura de inmunización. Es importante, además, recalcar comunicacionalmente que la vacunación debe ser acompañada por otras medidas, como el autocuidado, uso de mascarilla y el testeo, trazabilidad y aislamiento. 
Montero-Liberona - Comunicacionalmente, ¿qué aspectos piensa usted que podrían mejorar los países para abordar el tema de las vacunas y el covid-19, en general?

Kalergis - Aumentar la divulgación con base científica, ya que hace accesible el conocimiento a la población y es la forma más eficiente de socializar los nuevos resultados obtenidos, aumentando la presencia de científicos y profesionales de la salud en medios de comunicación. Creo que son importantes también los testimonios de personas que ya han sufrido las consecuencias de la enfermedad y de aquellas que se han vacunado y beneficiado de la inmunidad que les han conferido estas herramientas sanitarias. En el fondo, procurar que la comunicación relativa a vacunas y a las medidas de prevención del contagio tengan un elemento vivencial y personal, además de lo científico, técnico o profesional. Siempre con máxima transparencia y veracidad científica, empírica y vivencial.

Un mensaje que es fundamental transmitir corresponde al hecho de que la vacunación debe ser considerada solo como uno de los pilares de la estrategia contra la pandemia y sumarse a otras medidas, como la prevención del contagio por medio de elementos de protección personal, lavado de manos y distanciamiento físico. Otras medidas como el testeo, trazabilidad y aislamiento también deben ser destacadas y debidamente explicadas en los medios de comunicación como herramientas importantes para el control de la pandemia.

Montero-Liberona - ¿Qué factores piensa usted que influyen tanto positiva como negativamente en las percepciones sobre la seguridad de las vacunas hacia una mayor o menor vacunación del covid-19?

Kalergis - Las redes sociales han tenido un gran impacto tanto en la percepción como en la toma de decisiones con respecto al coronavirus o las vacunas de forma positiva o negativa. Por eso es muy importante utilizar como respaldo la evidencia científica disponible y contrarrestando la proliferación de información errónea o "infodemia". Me parece clave que las redes sociales puedan incorporar una mayor cantidad de información con base científica e idealmente conduciendo a las referencias en las que se encuentra esa información. Por supuesto, el esfuerzo de aumentar el contenido científico en redes sociales debe ir de la mano con la simplicidad y un lenguaje apropiado.

Montero-Liberona - ¿Qué mensajes usted construiría sobre la seguridad de la vacuna del covid-19 para ser comunicados a ciudadanos de diferentes países en Latinoamérica? Eventualmente, ¿cree que debiese existir un mensaje único o distintos tipos de mensajes?

Kalergis - Creo que deberíamos crear un mensaje único coherente y consecuente. Debido a que las vacunas son consideradas uno de los logros de salud pública más importante de la humanidad y una de las medidas de mayor impacto social, estas deben ser consideradas y comunicadas como bienes públicos que han permitido salvar miles de millones de vidas. Su descubrimiento y uso poblacional se remonta a varios siglos atrás y a todos los continentes, incluyendo las regiones más apartadas del planeta. Han permitido controlar muchas enfermedades de alto impacto e incluso erradicar algunas, como el caso de la viruela. Este último logro es el único ejemplo en la historia de la ciencia y la medicina, por medio del trabajo conjunto de disciplinas científicas como la inmunología y la microbiología. Contamos con más de 225 años de historia de vacunación $y$, a la fecha, se han desarrollado vacunas que nos han protegido contra al menos veinte enfermedades potencialmente mortales, las que han demostrado ser seguras y eficaces. El estudio y formulación de vacunas lleva cientos de años y, por ello, su desarrollo en esta emergencia sanitaria ha sido tan efectivo, ya que contamos con el conocimiento y la tecnología para obtener dosis que son seguras y efectivas. 
Montero-Liberona - Finalmente, ¿qué piensa del rol que han tenido diferentes organizaciones internacionales en salud en América Latina ante el covid-19y los procesos de vacunación en diferentes países?

Kalergis - El rol de algunas entidades internacionales como de la Organización Mundial de la Salud, la Organización Panamericana de la Salud, The Vaccine Alliance (GAVI), entre otras, han sido muy importantes tanto en la comunicación de información como en el manejo de esta pandemia. Estas instituciones han liderado, junto a otras instituciones, los nuevos lineamientos de acuerdo con información científica disponible y proporcionado financiamiento para iniciativas en el desarrollo de tecnologías, como las vacunas para afrontar la pandemia del covid-19. Este trabajo ha implicado grandes esfuerzos en conexión con la comunidad científica internacional, así como la dedicación plena de las diferentes entidades regulatorias de cada país. Estas últimas han realizado las revisiones necesarias para validar la calidad, seguridad, inmunogenicidad y eficacia de las vacunas y contribuir, de esa manera, a las políticas y campañas de inmunización en cada país.

Montero-Liberona - Dra. Xinia Fernández Delgado, ¿cuál es su visión ante lo que ha sucedido con la vacunación en su país Costa Rica-como en los demás países de Latinoamérica?

Delgado - El gobierno de Costa Rica en forma muy temprana anunció los esfuerzos y desarrollos en el tema de vacunas, y realizó diversas gestiones de negociación anticipada con diferentes proveedores para garantizar la llegada oportuna de vacunas a su nación. El país optó por vacunas con el respaldo de organismos internacionales y que estuvieran aprobadas por la FDA [Administración de Alimentos y Medicamentos]. A partir de diciembre de 2020 llegaron las primeras vacunas y en agosto de 2021 se contaba con una tasa de 58.7 de la población inoculada con una dosis y 19.4 con dos dosis. Probablemente esta cifra no impresiona, pero Costa Rica es un país pequeño, con poco más de 5 millones de habitantes. Solo están por sobre estas cifras de vacunación países como Chile, que ha seguido una estrategia muy particular, Uruguay y Brasil.

En general se observa una inequidad en la distribución de vacunas a nivel latinoamericano: algunos países con altas tasas de vacunación y otros apenas iniciando.

Costa Rica es un país con una cultura de vacunación importante. Hace muchos años se viene desarrollando un programa muy robusto, y las personas conocen y confían en ella. Pero, ya antes de que llegaran las vacunas, empezamos a trabajar en la confianza de los ciudadanos en estas, ya que por ser un desarrollo muy temprano podía generarse algún nivel de inseguridad en la población. Así, le recordamos a la población lo que han significado las vacunas en el tema de la polio y en otras enfermedades prevenibles.

Además, gradualmente, ejecutamos una estrategia que acompaña todo el proceso de vacunación. Como ha ocurrido en muchos países de Latinoamérica, el manejo de la pandemia no ha estado exento de problemas: crisis logísticas, crisis de gestión que, evidentemente, se traducen en crisis de comunicación. En nuestro país tenemos una prensa muy cuestionadora, lo cual es bueno. Pero ha supuesto un reto, inclusive, siendo uno de los factores importantes la llegada de vacunas que generaban expectativas en las personas.

Hemos enfrentado estos meses resistencia a aplicarse la vacuna en algunos sectores de la población, en comunidades muy específicas, y se está haciendo un esfuerzo desde la comunicación comunitaria para convencerlos de las ventajas de la vacunación.

Muchos sectores han demandado la vacuna y contamos con escasas cantidades disponibles. Por ello, tratar de aplacar la ansiedad de la población y de los distintos sectores ha sido un trabajo difícil. ¡Es que todos quieren ser prioritarios! 
Montero-Liberona - ¿Y cómo han reaccionado los diferentes sectores de la población?

Delgado - Costa Rica apostó, en primer lugar, por el personal de primera respuesta a cargo de los trabajadores de las instituciones de salud, de la Comisión Nacional de Emergencias, Cruz Roja, cuerpos policiales, entre otros. Ese grupo en conjunto con los adultos mayores que viven en lugares de larga estancia. En general, la respuesta de esos grupos siempre ha sido buena. Sin embargo, tenemos entre el personal de salud personas resistentes a vacunarse, lo que no ayuda a la difusión del mensaje de vacunación. Al contrario, los adultos mayores estuvieron todos muy contentos de inocularse, y aprovechamos de obtener sus testimonios en las redes sociales o en los medios de comunicación al momento de vacunarse. Pero, existen algunas regiones en donde incluso los hijos no han permitido que sus padres se vacunen por razones desde religiosas hasta el temor del efecto de la vacuna.

En general, puedo decir que la demanda ha sobrepasado en mucho la oferta de vacunas disponibles.

Montero-Liberona - ¿Y qué mensajes piensa usted que han funcionado?

Delgado - Hemos trabajado dos líneas: por una parte, lo informativo vinculado a un acompañamiento diario en el avance del proceso y, por otra parte, una comunicación más emotiva, utilizando el testimonio. Hemos llevado el mensaje a un nivel publicitario, utilizando varios encuadres y canales en redes sociales, considerando que la Caja [aludiendo a la organización en donde trabaja] tiene una red social bastante fuerte, para resaltar la importancia de la vacuna como protección a los adultos mayores.

El mensaje y los productos de comunicación se han ido adaptando al segmento de la población que se está vacunando. La comunicación es un proceso muy vivo, dinámico.

Creemos que el testimonio por imitación arrastra mucho a la gente. Por ejemplo, en un sector al norte del país teníamos personas de 110 años vacunándose y declarando que están "pura vida" [expresión costarricense para indicar que están muy bien], tal como decimos los "ticos" [lenguaje coloquial para referirse a los costarricenses], felices y recalcando que están súper bien, y que la vacunas no tienen efectos secundarios. Pero, aunque contamos con una tradición en vacunación, hemos tenido que enfrentarnos a nuevos retos como las fake news, al temor de lo nuevo con ideas como que nos van a implantar un chip o que es una estrategia de exterminación. Afortunadamente, ha existido un trabajo con mucho apoyo por parte de los medios de comunicación en que, a veces, la demanda de vacunas sobrepasa las posibilidades institucionales.

El equipo estratégico vacunador que lidera este proceso es pequeño, por lo que responder como voceros a todos los requerimientos de la prensa ha sido un reto. Además, se debe considerar la logística, la distribución de control de todo el proceso, la atención a los medios de comunicación. 0 sea, no hay día en que no tengamos tres o cuatro voceros en diferentes medios con entrevistas largas de media hora o una hora hablando sobre el proceso, respondiendo las inquietudes de la población. Ha sido un trabajo bastante intenso todos estos meses.

\section{Montero-Liberona - ¿Cuáles han sido los aspectos más complejos en esta comunicación en tiempos de pandemia?}

Delgado - A mi juicio, hay dos aspectos: en primera instancia, entender cómo manejar la ansiedad de la población ante el número específico de vacunas existentes utilizando la comunicación. Producto de esta poca disposición de vacunas, hemos escuchado que algunas personas que no estaban en el grupo uno [aludiendo al grupo prioritario] y que servían como funcionarios de salud adelantaron su vacunación. Afortunadamente, no hubo una figura tan destacada como algún ministro, pero sí funcionarios sobre todo en unidades locales que se saltaron el proceso, y eso fue muy difícil de manejar. 
Lo más duro, desde el punto de vista comunicacional, es lastimar el alma y la fibra de las personas, como cuando grabaron el momento en que a un adulto mayor lo estaban inoculando y, realmente, no se le aplicó el líquido. Su familia hizo el vídeo del momento en que se introduce la aguja y se vuelve a sacar, sin nada. Esto significó un momento muy complejo, porque se puso en riesgo todo el programa de vacunación, toda la confianza de la población en una institución que, en este país, es querida [refiriéndose a la Caja Costarricense del Seguro Social]. Entonces, presionamos para que la respuesta fuera inmediata y se hiciese pública: al final de esa misma mañana, se suspendió al funcionario y, dos días después, el Ministerio Público lo detuvo. Pero, el daño causado sigue todavía siendo importante. Vemos mucho en las redes sociales que todo el grupo que se vacunó en esa área de salud, por parte de ese funcionario, sigue teniendo dudas.

Otra respuesta fue, de inmediato, adaptar los protocolos. Se instruyó a todo el personal de la institución para que, a partir de ese día, se le muestre a la persona la jeringa, cuando se extrae el líquido, antes de aplicar que está el líquido, que se le aplica y, nuevamente, una vez aplicada que compruebe que la jeringa está vacía, todo para tratar de recuperar la confianza. Pero ha sido muy duro.

En general durante la pandemia el proceso de comunicación ha sido muy complejo, con altas demandas de los medios de comunicación todo el tiempo. Hemos enfrentado crisis constantes. Uno de los factores más importantes es el cansancio de la población y la resistencia a las medidas de restricción de circulación de vehículos, aforos y otras restricciones a las que no estamos acostumbrados.

\section{Montero-Liberona - ¿Cómo visualiza la labor de las organizaciones internacionales en salud respecto al covid-19?}

Delgado - El covid-19 ha sido una emergencia que tomó por sorpresa al mundo. Pienso que la labor de los organismos internacionales debe estar muy ligada en apoyar la coordinación de mensajes claves y el tema de investigación. Desconozco si esto sucede en todos los países de Latinoamérica, pero se necesita equilibrar los intereses tanto de la salud pública como aquellos de los otros sectores (económicos, culturales, ente otros). Por ejemplo, ha habido casos de mensajes desde la salud pública que no son coherentes con mensajes vinculados al cierre de locales, como una de las medidas más extremas de confinamiento. Por ello, pienso que el rol de las organizaciones va muy ligado a la coordinación y de evaluar cómo logramos un punto de equilibrio entre los intereses de los sectores.

Montero-Liberona - Mellanie Fontes-Dutra, ¿cómo caracterizaría usted las comunicaciones en América Latina respecto a la vacunación del covid-19?

Fontes-Dutra - En Brasil, el covid-19 ha sido muy duro. Son muchos elementos que actúan negativamente y que incrementan el peligro de contraer la enfermedad, tales como las noticias falsas, la desinformación y la información engañosa. Estos aspectos muchas veces se combinan en diferentes ámbitos, incluso provenientes del propio gobierno y del jefe de Estado. Nos falta una coordinación nacional para manejar el covid-19, y esto es un gran problema.

Lo más complejo es que disponemos de pocas estrategias para su mitigación, lo que se debe a la información engañosa que se difunde y a la cual las personas se exponen. Como resultado tenemos más riesgos de contagios, mayores tasas de hospitalización, entre otros.

Entre febrero y marzo del 2021, el sistema de salud de varias ciudades brasileñas han colapsado al mismo tiempo. Ha sido difícil ver que muchas localidades necesitaban ayuda, oxígeno, más camas [de UCI]... y, además, lo dañino que ha sido la información engañosa y la poca atención a las medidas de mitigación por parte de algunas personas. 
Por el momento, no ha mejorado la situación ni ha empeorado. Es extraña la estabilización en los casos diarios y nos preocupa mucho porque, con la llegada del invierno, deberán de aumentar los contagios, por lo que estamos esperando mayores tasas de hospitalización en el futuro próximo. Se viene la tercera ola.

Montero-Liberona - En el caso de Brasil, semejante a otros países en Latinoamérica, ¿existe una tradición en cuanto a los niveles de vacunación?

Fontes-Dutra - Aunque tenemos una tradición en vacunación, nuestro problema es la cantidad de vacunas por persona. Si bien en inoculación somos considerados un referente en el Hemisferio Sur, especialmente con la vacuna de la influenza, pero en cuanto a campañas de vacunación, desafortunadamente, el problema es la cantidad de vacunas.

Hoy muchas personas recibieron con retraso, respecto al intervalo correcto, la segunda dosis de AstraZeneca, por ejemplo, y algunas aún están esperando recibirla y se sienten preocupadas por la eficacia de esta vacuna. Si bien hay una aceptación a las vacunas por parte de algunas personas, hoy estamos pasando por un momento difícil para acceder a más vacunas. Por un lado, esto se debe a la relación diplomática de Brasil con otros países como China.

Montero-Liberona - ¿Y existen diferentes mensajes comunicacionales, tanto a nivel nacional como regional, para las personas sobre el covid-19?

Fontes-Dutra - Lamentablemente, los mensajes de las campañas sanitarias sobre el covid-19 han empezado tarde. Empezamos a verlos recientemente y nos preguntamos qué sucedió, ya que habría sido fundamental empezar a vincular los mensajes antes de que las vacunas llegaran. Por ejemplo, la comunicación nacional proveniente del Ministerio de Salud ha empezado este año.

Deberíamos haber iniciado la comunicación y el chequeo de información [aludiendo al fact checking] vinculando los mensajes antes de que llegaran las vacunas. Esto fue, sin duda, de gran contribución para otros países, porque las personas conocían el desarrollo de las vacunas, su importancia y cobertura. Tenemos que alcanzar esto en Brasil.

\section{Montero-Liberona - ¿Cuán tarde empezaron las campañas en Brasil?}

Fontes-Dutra - En febrero de este año empezamos a ver con mayor frecuencia estos mensajes por parte del Ministerio de Salud. Eventualmente, podrían haber comenzado a finales de 2020, posiblemente con una menor frecuencia.

\section{Montero-Liberona - ¿Qué percepciones tiene de lo sucedido en otros países latinoamericanos por el covid-19?}

Fontes-Dutra - Nosotros empezamos a observar más a Chile. Su tasa de vacunación es alta y sorprendente. Muchos datos para la CoronaVac y su efectividad han provenido y analizado a partir de los resultados de Chile. Es uno de los países que está liderando la vacunación en Latinoamérica, y sabemos que otras naciones de la región están efectuando las medidas de control mejor que nosotros. En resumen, Brasil ha fallado en la aplicación de medidas de mitigación más rigurosas cuando realmente las necesitábamos, a diferencia de otros países que lo hicieron.

Para mí, este negacionismo e información engañosa ha producido que las personas le tengan mayor miedo al cierre o la cuarentena que al mismo virus. Ya sabemos que estos cierres afectan nuestra economía, así como otras situaciones asociadas. 
Montero-Liberona - ¿Cómo visualiza el rol que han jugado las organizaciones internacionales en salud en controlar la pandemia?

Fontes-Dutra - Hemos tenido mucha información de la Organización Panamericana de la Salud y de organismos como el NIH [National Institutes of Health] y el FDA, especialmente sobre las vacunas, mientras que el Center for Disease Control (CDC) ha sido muy importante para orientar el manejo del covid-19 en hospitales. Sabemos que se están haciendo un excelente trabajo y que tiene como principal preocupación incrementar la confiabilidad de estas agencias en nuestra población frente a la información engañosa que circula.

\section{Montero-Liberona - ¿Y qué tipo de información engañosa es esa?}

Fontes-Dutra - Principalmente sobre el virus: que es un simple resfrío o que uno por ser deportista no puede enfermarse por su buena condición física, jtal como nuestro presidente! Hay personas que no confían en la vacuna porque es china; tenemos todo tipo de información engañosa sobre el virus, la pandemia, la vacuna de tal o cual país, y todo esto hace que las personas no se den cuenta de que esta situación es muy grave. La gente se expone al virus, no usan mascarillas, se aglomeran y van a todas partes sin la suficiente protección individual. Y nuestro mayor problema es no contar con una coordinación nacional para enfrentar este segundo año de la pandemia.

\section{Montero-Liberona - ¿Y existen organizaciones civiles que ayuden en momentos tan difíciles?}

Fontes-Dutra - Hay muchas organizaciones que dan a conocer mensajes e iniciativas solidarias en recaudar dinero para ayudar a las poblaciones más vulnerables en la compra de mascarillas, por ejemplo, para su protección y concientización.

Y contamos con muchos profesionales de la salud que trabajan en hospitales y entregan información a los medios de comunicación, como la televisión y la prensa, compartiendo sus preocupaciones ante las altas tasas de hospitalizaciones, el perfil de los pacientes en hospitales, etc.

Montero-Liberona - Y, para concluir esta conversación, realicemos un ejercicio. Si tuviera todo el presupuesto posible para combatir el covid-19 en Brasil a su disposición, ¿qué haría?

Fontes-Dutra - Había focalizado la comunicación sobre cómo se transmite el virus. Una parte del presupuesto sería destinado a crear mensajes para que enseñen a las personas cómo la transmisión del virus puede ser peligrosa, aunque parte de la población esté vacunada, a combatir el virus con el uso adecuado de mascarillas y a darle a la población la oportunidad de que, individualmente, puedan comprometerse con las acciones coordinadas por el gobierno.

\section{Montero-Liberona - ¿Y qué diría su mensaje final?}

Fontes-Dutra - Las personas deben conocer los riesgos que se enfrentan. De todos los mensajes, lo que más impacta es aquel que incluye las consecuencias y el riesgo para quien lo lee, para sus familias y seres queridos. Porque más que números ellos pueden ser tu mamá, tu papá, tu primo... ¡Ya no bastan tan solo los números! Debemos mostrarles a las personas que somos responsables de las tasas, y es nuestra responsabilidad ayudar a que todos estemos bien. 
Sin duda, cada uno de los entrevistados compartieron patrones vinculados a la relevancia de una comunicación exitosa en el ámbito de la salud. Ciertamente, el factor común fue que, previo a iniciar cualquier proceso de vacunación, la población debía estar comunicacionalmente preparada para vivir este proceso. Otro aspecto que surgió fue la necesidad de contar con coordinaciones nacionales en cada país. Finalmente, y no por ello menos importante, la importancia de acabar con los aspectos negativos vinculados a las noticias falsas, la desinformación y la información engañosa fueron compartidos por los tres expertos. Como comunicadores debemos estar capacitados y preparados para escenarios inesperados, listos para enfrentar cualquier crisis emergente en salud. Es así como algunos días contamos historias para levantar el ánimo. Otros días comunicamos noticias amargas. Pero, todos los días, aprendemos algo nuevo sobre cómo comunicarnos de manera efectiva durante los momentos más difíciles y por qué trabajar entre todos como un equipo en Latinoamérica es tan fundamental.

Artículo recibido el 03.09.2021 y aprobado el 21.10.2021. 